\title{
Cross-Cultural Adaptation and Validation of the MPAM-R to Brazilian Portuguese and Proposal of a New Method to Calculate Factor Scores
}

OPEN ACCESS

Edited by:

Pietro Cipresso,

IRCCS Istituto Auxologico Italiano,

Italy

Reviewed by:

Timo Partonen,

National Institute for Health and Welfare, Finland

Fabrizio Scrima,

University of Rouen, France

*Correspondence: Maicon R. Albuquerque lin.maicon@gmail.com

Specialty section: This article was submitted to Quantitative Psychology and Measurement, a section of the journal Frontiers in Psychology

Received: 30 November 2016 Accepted: 10 February 2017 Published: 28 February 2017

Citation:

Albuquerque MR, Lopes MC, de Paula JJ, Faria LO, Pereira EI and da Costa VT (2017)

Cross-Cultural Adaptation

and Validation of the MPAM- $R$ to Brazilian Portuquese and Proposal of a New Method to Calculate Factor

Scores. Front. Psychol. 8:261. doi: 10.3389/fpsyg.2017.00261

\section{Maicon R. Albuquerque ${ }^{*}$, Mariana C. Lopes ${ }^{2}$, Jonas J. de Paula ${ }^{3}$, Larissa O. Faria², Eveline T. Pereira ${ }^{2}$ and Varley T. da Costa ${ }^{1}$}

' Department of Sports, Universidade Federal de Minas Gerais, Belo Horizonte, Brazil, ${ }^{2}$ Department of Physical Education, Universidade Federal de Viçosa, Viçosa, Brazil, ${ }^{3}$ Department of Psychology, Faculdade de Ciências Médicas, Belo Horizonte, Brazil

In order to understand the reasons that lead individuals to practice physical activity, researchers developed the Motives for Physical Activity Measure-Revised (MPAM-R) scale. In 2010, a translation of MPAM-R to Portuguese and its validation was performed. However, psychometric measures were not acceptable. In addition, factor scores in some sports psychology scales are calculated by the mean of scores by items of the factor. Nevertheless, it seems appropriate that items with higher factor loadings, extracted by Factor Analysis, have greater weight in the factor score, as items with lower factor loadings have less weight in the factor score. The aims of the present study are to translate, validate the MPAM-R for Portuguese versions, and investigate agreement between two methods used to calculate factor scores. Three hundred volunteers who were involved in physical activity programs for at least 6 months were collected. Confirmatory Factor Analysis of the 30 items indicated that the version did not fit the model. After excluding four items, the final model with 26 items showed acceptable model fit measures by Exploratory Factor Analysis, as well as it conceptually supports the five factors as the original proposal. When two methods are compared to calculate factors scores, our results showed that only "Enjoyment" and "Appearance" factors showed agreement between methods to calculate factor scores. So, the Portuguese version of the MPAM-R can be used in a Brazilian context, and a new proposal for the calculation of the factor score seems to be promising.

Keywords: motives, physical activity, factor score, motivation, psychometry

\section{INTRODUCTION}

Physical activity is a well-documented method to reduce a number of diseases such as cardiovascular disease (Carnethon, 2009) and a widening variety of chronic diseases, including diabetes mellitus (Colberg et al., 2010; Burr et al., 2012b), cancer (Shi et al., 2015), obesity (Lakka and Bouchard, 2005), hypertension (Diaz and Shimbo, 2013), bone and joint diseases (Burr et al., 2012a). Physical activity is also a protective factor or useful intervention to reduce psychiatric symptoms in cognitive disorders (e.g., depression) (Lee et al., 2012) and improve cognitive functioning (Bamidis et al., 2014). Individuals of all ages, including healthy subjects, can achieve a number of benefits in different dimensions (physical, psychological, social, and emotional) through 
physical activity (Penedo and Dahn, 2005; Warburton et al., 2006; Vogel et al., 2009; Janssen and Leblanc, 2010). Nevertheless, Hallal et al. (2012) suggest that approximately $31 \%$ of adults and $80 \%$ of adolescents worldwide do not reach recommended levels of daily physical activity. Moreover, studies such as Lee et al. (2012) demonstrated that if inactivity decreased by $10 \%$, half a million deaths could be prevented every year. Therefore, it seems crucial to understanding why some people are active and others are not.

Although the underlying causes of why some people are active and others not are highly complex, motivation is a possible explanatory factor. Motivation is a key process that influences individuals' initiation and maintenance of behavior (Murcia et al., 2007a). The Self-Determination Theory (SDT) seems to be the most contemporary framework used to understand physical activity motivation and adherence (Hagger and Chatzisarantis, 2008; Molanorouzi et al., 2015). Based on SDT, motivation to engage and adherence to physical activity need to be distinguished, and the most basic distinction is between intrinsic and extrinsic motivation (Ryan and Deci, 2000a). Intrinsic motivation refers to doing something because it is inherently interesting or enjoyable (Ryan and Deci, 2000a,b). For instance, a Taekwondo practitioner who practices for enjoyment and challenge involved in the sport is said to be intrinsically motivated (Ryan et al., 1997). In the other hand, extrinsic motivation refers to engaging in an activity for instrumental reasons, such as rewards (Ryan and Deci, 2000a,b). For example, an aerobics practitioner who practices your activity for improving his appearance is said to be extrinsically motivated (Ryan et al., 1997).

In order to understand the motives for physical activity, Ryan et al. (1997) developed a scale named Motives for Physical Activity Measure-Revised (MPAM-R) where used as the theoretical background of the SDT. The scale was composed by 30 items divided into five factors: (1) Fitness; (2) Appearance; (3) Competence/Challenge; (4) Social; and (5) Enjoyment. In summary, the original scale showed acceptable psychometric properties by Exploratory Factor Analysis (EFA) and Cronbach's alpha ranging between 0.78 to 0.92 .

To the best of our knowledge, this scale was translated and cross-culturally adapted in three studies and two languages. Celis-Merchán (2006) performed the adaptation of the Spanish version of the MPAM-R on a sample of 120 Colombian subjects. Cronbach's alpha of the Celis-Merchán (2006) study range between 0.75 to 0.91 . In addition, the authors performed an EFA that showed several problems (Celis-Merchán, 2006). Murcia et al. (2007b) adapted MPAM-R for the Spanish population in a large sample size (464 subjects). The final version of the scale purpose by the Murcia et al. (2007b) was composed by the 28 items with acceptable results by the EFA. In addition, the Cronbach's alpha range between 0.80 to 0.87 . Finally, Gonçalves and Alchieri (2010) performed the cross-cultural adaptation and validation of the scale for Brazilian Portuguese version. The results showed that the 26 items were not acceptable using Confirmatory Factor Analysis (CFA) standards $\left[\chi^{2}{ }_{(289)}=757.75\right.$; $\mathrm{GFI}=0.83$; AGFI $=0.80$, and RMSE $=0.07]$, although the authors considered that the values were acceptable. In addition,
Gonçalves and Alchieri (2010) results showed acceptable values of the Cronbach's alpha (between 0.75 to 0.88 ). Therefore, results around MPAM-R Brazilian version suggest the importance of psychometric review.

Moreover, in all MPAM-R versions, the factor scores are calculated by the mean of scores by items of the factor (for example, mean of the scores of the items 6,15,21,28, and 30 for social factor in MPAM-R). Although, this method is largely used in Sports Psychology Scales (Lonsdale et al., 2008; Pelletier et al., 2013) there are several other methods (for more details, see DiStefano et al., 2009), that can be interesting. One option would be the weighted method (DiStefano et al., 2009), that used the factor loading extracted by the EFA or CFA. In the common method (mean of scores by items), all items on a factor are given equal weight, regardless of the factor loading value extracted in EFA or CFA. In summary, the common method does not involve item loading values, thereby disregarding the strength (or weight) for each item. Therefore, items with relatively low loading values are given the same weight in the factor score as items with higher loading values. On the another hand, in the weighted method, the factor score is based on factor loading extracted by EFA or CFA, to each item. Therefore, one advantage this method is that items with higher factor loadings have greater weight in the factor score, as items with lower factor loadings have less weight have less weight in the factor score (DiStefano et al., 2009).

Thus, the present study aims to perform a new translation and cultural adaptation of the MPAM-R for the Portuguese languages and analyze its psychometric properties. In addition, verify the agreement between common (mean by items) and weighted methods to calculate factor scores.

\section{MATERIALS AND METHODS}

\section{Cross-Cultural Adaptation}

Initially, we contacted the researcher responsible for the scale to request his authorization to conduct the MPAM-R scale translation. After his approval, we started the translation process. The cross-cultural adaptation (Figure 1) began with a translation of the original scale of the MPAM- $\mathrm{R}$ into the Portuguese language. This step was carried out by two translators were native Portuguese speakers and had fluent English. The translations were independent, with two Portuguese versions (T1 and T2) of the scale being produced. A group of two Ph.D.'s with experience in Cross-Cultural Adaptation compared the different translations and evaluated semantic discrepancies, including any linguistic or conceptual issues. Secondly, a synthesis of the translations was obtained. The synthesis (T1 - T2) was independently backtranslated to English (BT1 and BT2) by two translators who have English as their mother tongue. The same group of two Ph.D.'s. merged the two back translations into the final Portuguese version of MPAM-R (P-MPAM-R).

\section{Validation \\ Sample}

The final stage of adaptation process suggested by Beaton et al. (2000) is the pre-test. According to Beaton et al. (2000), the 


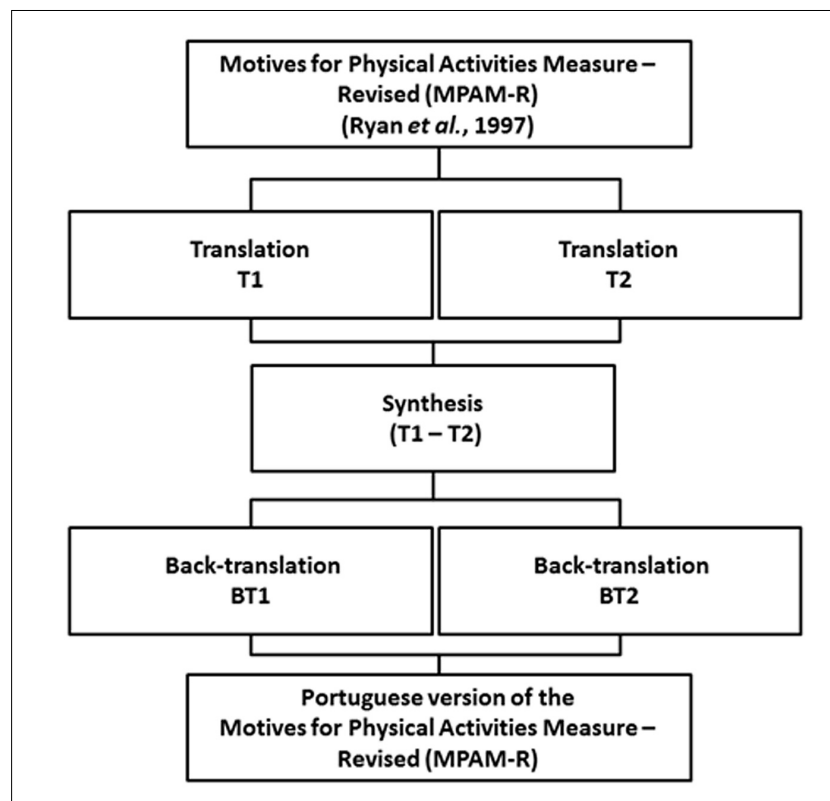

FIGURE 1 | Summary of the cross-cultural adaptation method.

recommend sample size for this stage should range from 30 and 40 individuals. We increased this suggestion for a convenience sample of 300 individuals attending four different gyms (more details in Table 1) with a mean of age of $28.37( \pm 7.11)$ years, who are enrolled in physical activities programs for at least 6 months (mean of regular physical activity practices of $51.60 \pm 28.82$ months). The sample size was increased in order to perform more robust statistical analysis (e.g., CFA and/or EFA). In addition, our sample size is in accordance with most used recommendation (Brown, 2006; Kline, 2011) for EFA and CFA, which is a ratio of 10:1 (ratio of the number of the subjects per number of items). The study was approved by the ethical committee of the Universidade Federal de Viçosa, and participants signed an informed consent after receiving a full explanation of the study.

TABLE 1 | Sample characteristics.

Sex
Male
Female
Education level
Undergraduate
Graduated
Marital status
Married/living with partner
Single/divorced/widowed
Types of activity
Weight training
Swimming
Dancing
Martial Arts

\section{Procedures}

At the beginning, contact was made with the manager of the gyms in which all the research objectives and procedures were presented. Afterward, the volunteers were personally invited to participate in the study. All volunteers were informed of the objectives and all procedures of the study, and were informed that would not receive any financial benefit from participation. All those who were willing to participate and had enough time available to respond to the instrument were selected. The scale was applied individually in the appropriate room (comfortable chair and table; without noise), before the regular physical activity practice.

\section{Instrument}

The original Motivation for Physical Activities Measure-Revised (MPAM-R) is composed by 30 items in five general motives for physical (factors): Enjoyment (seven items); Competence (seven items); Appearance (six items), Fitness (five items), and Social (five items). Items should be responded in 7-point Likert scale (1 - "not at all true for me" to 7 - "very true for me") (Ryan et al., 1997).

\section{Statistical Analysis}

Kaiser-Meyer-Olkin (KMO) measure of sampling adequacy and Bartlett's test of sphericity were used for the evaluation of model sufficiency (Field, 2009). High values of KMO (more than 0.70) generally indicate that a factor analysis may be useful with the data (Field, 2009). Bartlett's test of sphericity tests the hypothesis that a correlation matrix is an identity matrix, which would indicate that variables are unrelated and therefore unsuitable for structure detection (Field, 2009). Values lower than 0.05 of significance probability indicate a satisfactory factor analysis. CFA and EFA were conducted in order to assess the model fit of the original model. Weighted least squared method (WLSMV) estimator was used since it recommended as a good alternative when data are non-normal due to the ordinal nature (e.g., a Likert-type scale of fewer than seven points) of the scale (Chen et al., 2015).

As suggested by some authors (e.g., Brown, 2006; Kline, 2011), Root Mean Square Error of Approximation (RMSEA), Comparative Fit Index (CFI), Tucker-Lewis Index (TLI), and Standardized Root Mean Square Residual (SRMR) were used to evaluate the model fit. In addition, to minimize the impact of sample size on the model we examined the Relative ChiSquare $(\chi 2 / d f)$. The Relative Chi-Square is a measure to evaluate overall model fit; a value as low as 2.0 was recommended for a good model fit. A cut-off criterion equal or higher than 0.90 was recommended for the CFI and TLI. In addition, RMSEA and SRMR values less than 0.08 are considered acceptable. EFA using Geomin oblique rotation method was conducted, when necessary. In addition, instrument's internal reliability (Cronbach's alpha $\alpha \geq 0.70$ ) was computed.

In order to calculate factor scores, we adapt the weighted method (DiStefano et al., 2009). Firstly, sums of the factor loadings are calculated. Secondly, item's factor loadings are standardized by the sum of factor loadings. Then, factor score 
is computed by the sum of each item score by multiplying the standardized factor loading by the score of the item. For instance, in a five items factor (Factor loading - Item $1=0.80$; Item $2=0.60$; Item $3=0.40$; Item $4=0.60$; Item $2=0.80)$, the sum of the factor loading is 3.20 ( $\Sigma$ of the factor loading of the item 1 to 5 ). The standardized factor loading of the items are: Item $1-0.80 / 3.20=0.25$; Item $2-$ $0.60 / 3.20=0.19$; Item $3-0.40 / 3.20=0.13$; Item $4-0.60 / 3.20=$ 0.19 ; Item $5-0.80 / 3.20=0.25$. Assuming this hypothetical example that subject one scored 7 ("Very true for me") on all items, the factor score of the subject is $7\left[\left(7^{*} 0.25\right)+\left(7^{*} 0.19\right)\right.$ $\left.+\left(7^{*} 0.13\right)+\left(7^{*} 0.19\right)+\left(7^{*} 0.25\right)\right]$. Finally, to verify agreement between factors scores by weighted method and by common method (mean of the scores), we used Bland and Altman plots (Bland and Altman, 1999) and Paired $t$-test (Field, 2009).

\section{RESULTS}

\section{Cross-Cultural Adaptation}

The original and translated Portuguese versions of the MPAM-R are showed in Table 2.

\section{Psychometric Properties}

Firstly, we analyzes descriptive data through the KMO measure of sampling adequacy $(\mathrm{KMO}=0.925)$ and the Barlett's test of sphericity $<0.001$.

Then, the Cronbach's alpha was conducted to the initial proposal of 30 items, in which all dimensions showed values higher than 0.70. Despite favorable results of Cronbach's alpha (Table 3), the CFA of the original model (30 items) demonstrated that the model fit index measures were not satisfactory $\left(\mathrm{CFI}=0.89 ; \mathrm{TLI}=0.87\right.$; $\mathrm{RMSEA}=0.103 \mathrm{e} ; \chi^{2}=1661.165 \mathrm{e}$ $\mathrm{gl}=395 ; p<0.001)$.

As the model fit index measures of the original model were not satisfactory, an EFA with five factors was made. Those analysis

TABLE 3 | Cronbach's alpha of the 30 and 26 items versions.

\begin{tabular}{lcc}
\hline & 30 items & $\mathbf{2 6}$ items \\
\hline Enjoyment & 0.92 & 0.92 \\
Competence & 0.88 & 0.86 \\
Appearance & 0.76 & 0.76 \\
Fitness & 0.79 & 0.80 \\
Social & 0.83 & 0.83
\end{tabular}

TABLE 2 | Translation of the Motives for Physical Activity Measure Revised (MPAM-R).

\begin{tabular}{|c|c|c|}
\hline & Original version & Portuguese version \\
\hline 1. & Because I want to be physically fit. & Por que eu quero ficar fisicamente em forma. \\
\hline 2. & Because it's fun. & Por que é prazeroso. \\
\hline 3. & Because I like engaging in activities which physically challenge me. & Por que gosto de praticar atividades fisicamente desafiadoras. \\
\hline 4. & Because I want to obtain new skills. & Por que quero aprender novas habilidades. \\
\hline 5. & Because I want to look or maintain weight so I look better. & Por que quero perder ou manter o peso e ter uma melhor aparência. \\
\hline 6. & Because I want to be with my friends. & Por que quero encontrar meus amigos. \\
\hline 7. & Because I like to do this activity. & Por que gosto de praticar essa atividade. \\
\hline 8. & Because I want to improve existing skills. & Por que quero melhorar as habilidades que já tenho. \\
\hline 9. & Because I like the challenge. & Por que gosto do desafio. \\
\hline 10. & Because I want to define my muscles so I look better. & Por que quero definir meus músculos e ter uma melhor aparência. \\
\hline 11. & Because it makes me happy. & Por que fico feliz. \\
\hline 12. & Because I want to keep up my current skill level. & Por que quero manter meu nível de habilidade atual. \\
\hline 13. & Because I want to have more energy. & Por que quero ter mais energia. \\
\hline 14. & Because I like activities which are physically challenging. & Por que gosto de atividades fisicamente desafiadoras. \\
\hline 15. & Because I like to be with others who are interested in this activity. & Por que gosto da companhia de outras pessoas interessadas nessa atividade. \\
\hline 16. & Because I want to improve my cardiovascular fitness. & Por que quero melhorar minha condição cardiovascular. \\
\hline 17. & Because I want to improve my appearance. & Por que quero melhorar a minha aparência. \\
\hline 18. & Because I think it's interesting. & Por que acho que é interessante. \\
\hline 19. & Because I want to maintain my physical strength to live a healthy life. & Por que quero manter minha força física para levar uma vida saudável. \\
\hline 20. & Because I want to be attractive to others. & Por que quero que os outros me achem atraente. \\
\hline 21. & Because I want to meet new people. & Por que quero conhecer novas pessoas. \\
\hline 22. & Because I enjoy this activity. & Por que gosto dessa atividade. \\
\hline 23. & Because I want to maintain my physical health and well-being. & Por que quero manter minha saúde física e bem-estar. \\
\hline 24 & Because I want to improve my body shape. & Por que quero melhorar a forma de meu corpo. \\
\hline 25. & Because I want to get better at my activity. & Por que quero melhorar na minha atividade. \\
\hline 26. & Because I find this activity stimulating. & Por que acho essa atividade estimulante. \\
\hline 27. & Because I will feel physically unattractive if I don't. & Por que me acho fisicamente feio se não o fizer. \\
\hline 28. & Because my friends want me to. & Por que meus amigos querem que eu o pratique. \\
\hline 29. & Because I like the excitement of participation. & Por que gosto do prazer de participar. \\
\hline 30. & Because I enjoy spending time with others doing this activity. & Por que gosto de passar tempo com outras pessoas praticando essa atividade. \\
\hline
\end{tabular}




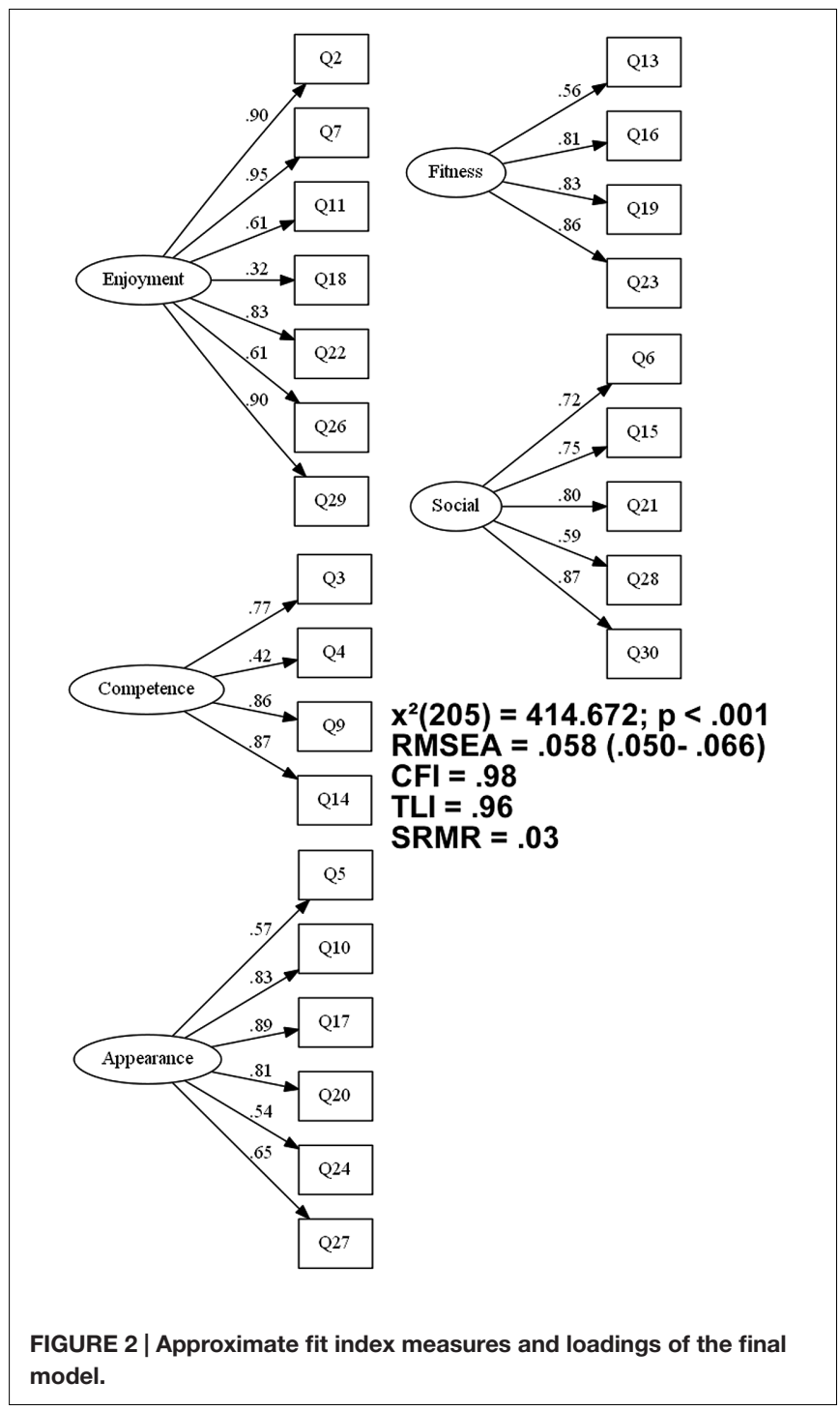

results showed positive approximate fit index $(\mathrm{CFI}=0.98$; $\mathrm{TLI}=0.96$; $\mathrm{RMSEA}=0.056 \mathrm{e} ; \chi^{2}=567.813$ and $\mathrm{gl}=295$; $p<0.001)$. However, some items carried in dimensions that were not conceptually appropriate and items with factor loading lower than 0.30 were found. Therefore, the items with loading higher than 0.30 in two dimensions ( 8 and 25) or with factor loading lower than 0.30 in dimensions that were conceptually considered in the original model (1 and 12) were removed from the next analysis. After the withdrawal of the four items, the final model (Figure 2) came up with acceptable fit index $(\mathrm{CFI}=0.98$; $\mathrm{TLI}=0.96 ; \mathrm{RMSEA}=0.058 \mathrm{e} ; \chi^{2}=414.672 \mathrm{e} \mathrm{gl}=205 ; p<0.001$. Furthermore, all values of Cronbach's alpha were higher than 0.70 in all dimensions (Table 3).

\section{Agreement between of Factor Scores}

Factor scores formula extracted by the factor loading (Figure 2) of the EFA of MPAR-R's final version to calculate the factor scores by weighted method are shown below:
- Enjoyment $=\left[(\mathrm{Q} 2 * 0.18)+\left(\mathrm{Q} 7^{*} 0.18\right)+\left(\mathrm{Q} 11^{*} 0.12\right)\right.$ $\left.+\left(\mathrm{Q} 18^{*} 0.06\right)+\left(\mathrm{Q} 22^{*} 0.16\right)+\left(\mathrm{Q} 26^{*} 0.12\right)+\left(\mathrm{Q} 29^{*} 0.18\right)\right]$

- Competence $=\left[(\mathrm{Q} 3 * 0.26)+(\mathrm{Q} 4 * 0.14)+\left(\mathrm{Q} 9^{*} 0.30\right)\right.$ $\left.+\left(\mathrm{Q} 14^{*} 0.30\right)\right]$

- Appearance $=\left[\left(\mathrm{Q}^{*} 0.13\right)+\left(\mathrm{Q} 10^{*} 0.19\right)+\left(\mathrm{Q} 17^{*} 0.21\right)\right.$ $\left.+\left(\mathrm{Q} 20^{*} 0.19\right)+\left(\mathrm{Q} 24^{*} 0.13\right)+\left(\mathrm{Q} 27^{*} 0.15\right)\right]$

- Fitness $=\left[\left(\mathrm{Q} 13^{*} 0.18\right)+\left(\mathrm{Q} 16^{*} 0.27\right)+\left(\mathrm{Q} 19^{*} 0.27\right)\right.$ $+(\mathrm{Q} 23 * 0.28)]$

- Social $=\left[\left(\mathrm{Q} 6^{*} 0.19\right)+\left(\mathrm{Q} 15^{*} 0.20\right)+\left(\mathrm{Q} 21^{*} 0.22\right)\right.$ $\left.\left.+\mathrm{Q} 28^{*} 0.16\right)+\left(\mathrm{Q} 30^{*} 0.23\right)\right]$

Bland and Altman plots of data from weighted and common methods (mean of the item scores) are showed in Figure 3. In "Enjoyment" [mean bias of 0.01 lower $(-0.33)$ and upper (0.36) 95\% confidence interval] and "Appearance" [mean bias of 0.00 lower $(-0.17)$ and upper (0.18) 95\% confidence interval] factors produced a lower mean bias than others factors when agreements between weighted and common (mean of the item scores) methods are analyzed. In addition, Table 4 showed analysis by Paired $t$-test that did not show significant differences in "Enjoyment" $[t(299)=1.33 ; p=0.184]$ and "Appearance" $[t(299)=0.83 ; p=0.409]$ factors scores between weighted and common (mean of the item scores) methods. All others comparisons were significant $(p<0.001)$.

\section{Normative Data}

Table 5 shows normative data for the Portuguese version of MPAR-R.

\section{DISCUSSION}

The aim of this study was to perform a cultural adaptation of the MPAM-R for the Portuguese languages, analyze its psychometric properties and compare the factor loadings calculated by mean and by weighted method. In summary, although the Portuguese version of the MPAM-R has fewer items when compared with the original version (Ryan et al., 1997), our version had acceptable psychometric proprieties and internal consistency. In addition, our results showed that the factor score calculated by mean and by the weighted method are different in three of the five factors.

In general, most of the sports psychology scales were developed in English-speaking countries, so cross-cultural and international collaborative studies, as well as the possibility of testing theories are needed. Thus, researchers need reliable and valid instruments in other languages. Nowadays, there are wellestablished methodological approaches for translating, adapting and validating instruments (Beaton et al., 2000; Sperber, 2004). Although, there was no clear consensus on how each method should be used. To the best of our knowledge, the MPAM-R was adapted to Spanish (Celis-Merchán, 2006; Murcia et al., 2007b) and Portuguese (Gonçalves and Alchieri, 2010). In general, the translation process used by those of studies was quite mixed, being more (Gonçalves and Alchieri, 2010) or less rigorous (Celis-Merchán, 2006). Thus, ours and Gonçalves and Alchieri (2010) studies have used the most rigorous approaches for translating the MPAM-R. 

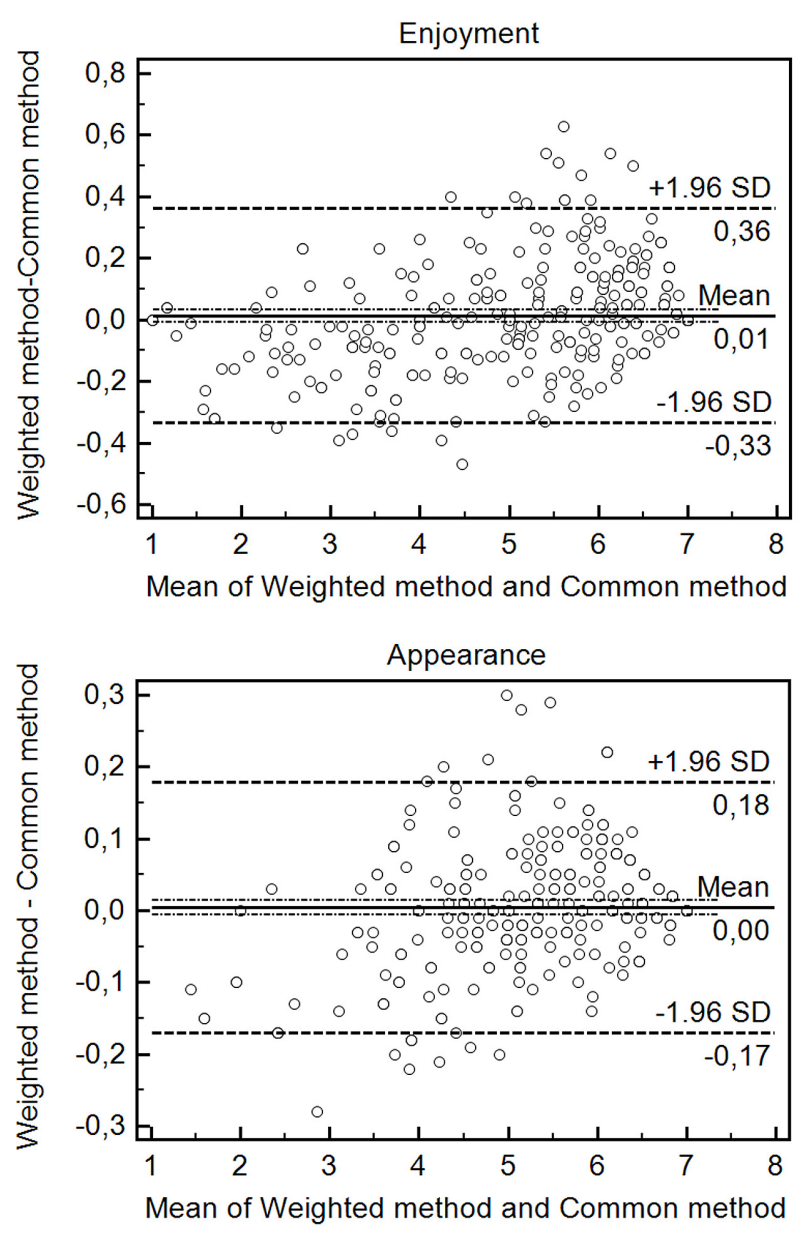
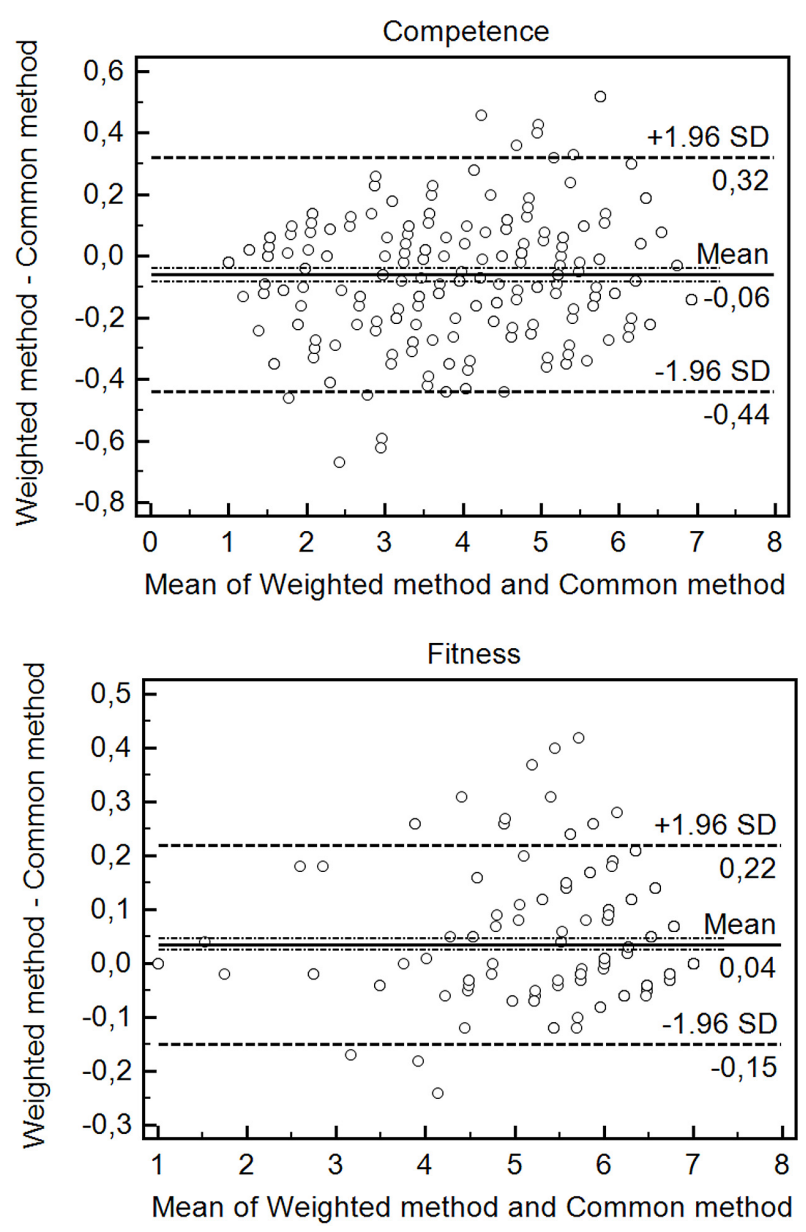

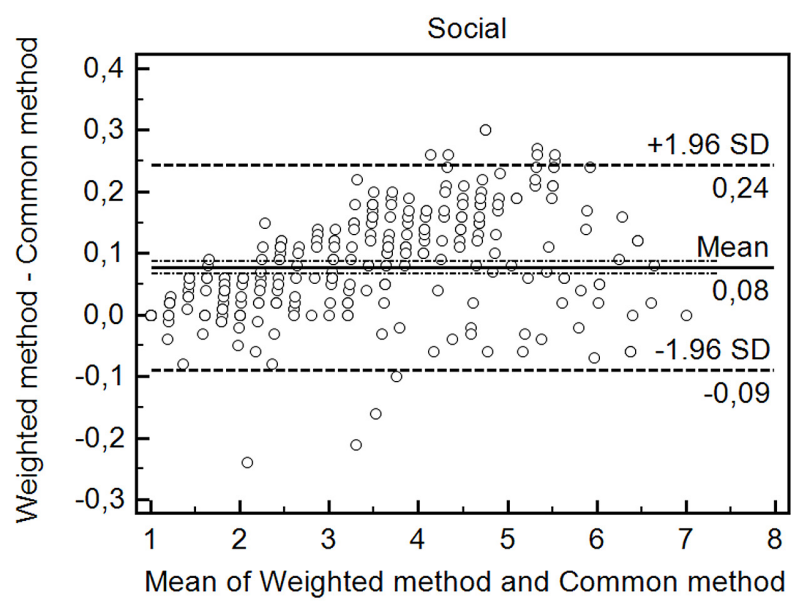

FIGURE 3 | Bland-Altman plots. The dashed bold lines represent the mean difference score. The dashed lines represent the limits of agreement (mean $\pm 1.96 \times$ the standard deviation of the difference score).

EFA and CFA are widely used multivariate statistical procedures that serve as tool to scale validation. EFA was used in Spanish versions (Celis-Merchán, 2006; Murcia et al., 2007b). However, EFA in Celis-Merchán (2006) study showed many problems. Instead, EFA showed acceptable results in the final version of the scale purpose by the Murcia et al. (2007b). Although the use of EFA is an interesting and useful method in scales validation, it is important to note that none of the Spanish studies performed an assessment of model fit. Model fit is obtained through the several statistical tests used 
TABLE 4 | Comparison between weighted methods and common method.

\begin{tabular}{|c|c|c|c|c|c|}
\hline \multirow[t]{2}{*}{ Factor } & \multicolumn{2}{|c|}{$\begin{array}{l}\text { Weighted method } \\
\qquad(n=300)\end{array}$} & \multicolumn{2}{|c|}{$\begin{array}{l}\text { Common method } \\
\qquad(n=300)\end{array}$} & \multirow[t]{2}{*}{$P$-value } \\
\hline & Mean & $S D$ & Mean & $S D$ & \\
\hline Enjoyment & 5.15 & 1.56 & 5.13 & 1.50 & 0.184 \\
\hline Competence & 3.86 & 1.70 & 3.92 & 1.69 & $<0.001^{*}$ \\
\hline Appearance & 5.30 & 1.20 & 5.29 & 1.17 & 0.409 \\
\hline Fitness & 6.11 & 1.11 & 6.07 & 1.11 & $<0.001^{*}$ \\
\hline Social & 3.32 & 1.53 & 3.24 & 1.49 & $<0.001^{*}$ \\
\hline
\end{tabular}

to determine how well the model fits to the data (Brown, 2006; Kline, 2011) and it is considered a robust statistical technique to validate scales. Unlike the Spanish versions (CelisMerchán, 2006; Murcia et al., 2007b), Gonçalves and Alchieri (2010) performed a CFA and reported model fit. However, using the recommendations indicated by some authors (Brown, 2006; Kline, 2011), the results showed that model fit was not acceptable $\left[\chi^{2}{ }_{(289)}=757.75\right.$; GFI $=0.83$; AGFI $=0.80$, and RMSE $=0.07]$, although the authors considered acceptable. A similar model fit as also found in another study (Wilson et al., 2002) that aimed to verify the psychometric properties of the MPAM-R. Meanwhile the authors considered that the values were not acceptable. Thus, our study used rigorous statistical approaches and the final version of the MPAM-R indicated that all parameters recommended for an excellent model fit were found $\left[X^{2}(205)=414.672 ; p<0.001\right.$; CFI $=0.98$; TLI $=0.97$; RMSEA $=0.058$; SRMR $=0.03]$.
Reducing the number of items is a common practice among translation and cross-cultural adaptation of scales. Especially in MPAM-R, Murcia et al.'s (2007b) and Gonçalves and Alchieri's (2010) studies had final versions with 28 and 26 items, respectively. In the present study, two items were excluded due to factor loading higher than 0.30 in two dimensions (8: "to improve existing skills" and 25: "to get better at activity"); and other two items were excluded because showed factor loading lower than 0.30 in dimension that were conceptually contemplated by the original model (1: "want to be physically fit" and 12: "to keep up current skill level"). Although the P-MPAM-R has a smaller number of items than the original scale, the psychometric properties showed good values. Furthermore, the smaller the scale is, the shorter will be the time for your application, which ease data collection process. Moreover, as in other studies (CelisMerchán, 2006; Murcia et al., 2007b; Gonçalves and Alchieri, 2010), the final version of the scale presented the same structure of five factors (enjoying, competence, appearance, fitness, and social) found in the original study (Ryan et al., 1997).

Regarding reliability, Cronbach's alpha is a generalization of the internal consistency reliability coefficient (Field, 2009). As can be seen in Table 6 all versions (Ryan et al., 1997; Murcia et al., 2007b; Gonçalves and Alchieri, 2010), including the present study, showed higher values than recommended $(>0.70)$.

In the Brazilian context, other scales can be used to investigate the motives to physical activity, since that the most used is IMPRAFE (Motivation to Regular Physical Activity Inventory (in Portuguese "Inventário de Motivação para a Prática de Atividade Física") (Barbosa, 2006). The scales were composed by some

TABLE 5 | Interpretative parameters of the MPAM-R for Weighted and Common Methods.

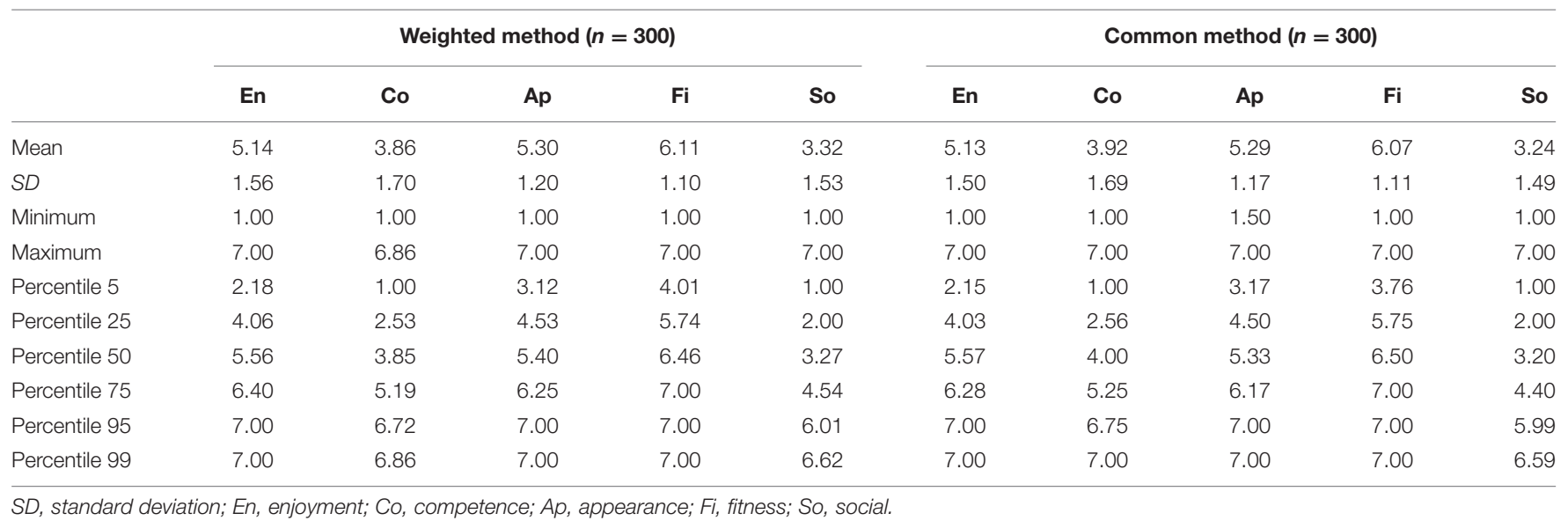

TABLE 6 | Cronbach's alpha Index to the MPAM-R in different studies.

Studies

Cronbach's alpha index by dimensions

\begin{tabular}{lcccr} 
& Enjoyment & Competence & Appearance & Fitness \\
\hline Ryan et al., 1997 & 0.92 & 0.88 & 0.91 & 0.78 \\
Celis-Merchán, 2006 & 0.75 & 0.87 & 0.90 & 0.83 \\
Murcia et al., 2007b & 0.84 & 0.85 & 0.87 & 0.81 \\
Gonçalves and Alchieri, 2010 & 0.88 & 0.75 & 0.79 & 0.80 \\
Present study & 0.92 & 0.86 & 0.76 & 0.84 \\
\end{tabular}


factors named: stress control, social, competence, appearance, enjoyment and fitness. Barbosa (2006) conducted the validation process of the IMPRAFE with 126 items and its short version with 48 items. As in Gonçalves and Alchieri (2010) study the results showed that in 120 items version of the IMPRAFE, the model fit was not acceptable $[\mathrm{GFI}=0.859$, AGFI $=0.854$ and $\mathrm{RMS}=0.065]$. However, the short version with 48 items showed satisfactory $[\mathrm{GFI}=0.952$, AGFI $=0.948$ and $\mathrm{RMS}=0.058]$. In both versions, the IMPRAFE showed Cronbach's alpha higher than 0.70. In summary, the IMPRAFE-short version (Barbosa, 2006) can be an excellent scale to investigate Motivation for Physical Activity in a Brazilian context. However, the fact that was not translated or adapted to other contexts (for example, English) does not allow cross-cultural and international collaborative studies. In addition, the fewer of items of MPAM-R reduces application time to IMPRAFE, which facilitate data collection process.

Overall, the present study compared two ways to calculate the factor score. In general, factor scores are calculated by the mean of scores by items of the factor. Therefore, when performing this procedure it is suggested that all items have the same weight for factor calculation. However, in EFA or CFA, the factor loadings show that some items load more than others in the same latent variable. For this reason, we believe that the current way factor scores are calculated needs to be reviewed, though being largely used. In the present study, we used an adaptation of the weighted method (DiStefano et al., 2009), that used the factor loading extracted by the EFA to create weights for each item of the factor. Our results showed that when compared two methods to calculate factors scores, only "Enjoyment" and "Appearance" factors showed agreement between methods to calculate factor scores. On the other hand, Paired $t$-test found that all others comparisons were significant $(p<0.001)$. Hence, values calculated by the two methods exhibit statistical significant differences. In addition, disagreements (see Figure 3) of this factors ("Competence"; "Fitness"; and "Social") do not present a pattern (e.g., overestimation or underestimation the values). Thus, it is possible to consider that the theoretical changes in the way of calculating the factor score modified the results. Basically, we considered that the weighted method proposed in the present study presents a more appropriate theoretical background. For this reason, we believe that the weighted method can be a more appropriate alternative to calculating factor scores. Although even more refined methods exist (for more details, see DiStefano et al., 2009) we chose to adapt the weighted method because it enables the comparison between the factors since the units of measure are the same as the original scale (variation between 1 and 7). In conclusion, we believed that our not much common weighted method could be an alternative to calculating factor

\section{REFERENCES}

Bamidis, P. D., Vivas, A. B., Styliadis, C., Frantzidis, C., Klados, M., Schlee, W., et al. (2014). A review of physical and cognitive interventions in aging. Neurosci. Biobehav. Rev. 44, 206-220. doi: 10.1016/j.neubiorev.2014. 03.019 scores, once it takes into account the factor loading of the item extracted by the Factorial Analysis.

Our study suffers from some limitations. Firstly, reliability, in a practical definition, is the ability of an instrument to measure consistently (Hopkins, 2000), and it is closely associated with its validity (Tavakol and Dennick, 2011). In the present study, we used the Cronbach's alpha as the reliability measure, however, this measure has received a lot of criticism (Sijtsma, 2009). Although understanding the limitations to the Cronbach's alpha (Sijtsma, 2009), and that other methods could have been used (Hopkins, 2000), we chose it because it is probably the most used reliability measure in scales validation, as well as, all other studies (CelisMerchán, 2006; Murcia et al., 2007b; Gonçalves and Alchieri, 2010), including the original scale (Ryan et al., 1997), also used this reliability measure. In the end, it was not possible to test our final model proposed by the EFA with a new CFA in a different and large sample, however, this may be a proposal for further study.

\section{CONCLUSION}

The present study provides evidence of validity and excellent psychometrics properties of the Portuguese version of the MPAM-R in which 7-items measure enjoyment, 4-items measure competence, 6-items measure appearance, 4-items measure fitness, and 5-items measure social. Therefore, the Portuguese version of the MPAM-R may be used appropriately and successfully to measure the motives for physical activity. In addition, we showed another way to calculate factor score named weighted method that is different from the common method (mean of the score), but can be a more appropriate alternative to calculate factor scores.

\section{AUTHOR CONTRIBUTIONS}

MA, ML, JdP, and VdC designed the study and analyzed data. LF collected the data. All authors participated in the interpretation of the data. MA drafted the manuscript. All authors helped with the writing of the manuscript. All authors approved the final version of the manuscript submitted for publication.

\section{FUNDING}

This study was funded by Fundação de Amparo à Pesquisa do Estado de Minas Gerais (FAPEMIG) and Pró-Reitoria de Pesquisa da Universidade Federal de Minas Gerais (UFMG).

Barbosa, M. L. L. (2006). Propriedades Métricas do Inventário de Motivação à Prática Regular de Atividade Física (IMPRAF-126). Master's Thesis, Universidade Federal do Rio Grande do Sul, Porto Alegre.

Beaton, D. E., Bombardier, C., Guillemin, F., and Ferraz, M. B. (2000). Guidelines for the process of cross-cultural adaptation of self-report measures. Spine 25, 3186-3191. doi: 10.1097/00007632-200012150-00014 
Bland, J. M., and Altman, D. G. (1999). Measuring agreement in method comparison studies. Stat. Methods Med. Res. 8, 135-160. doi: 10.1191/ 096228099673819272

Brown, T. A. (2006). Confirmatory Factor Analysis for Applied Research. New York, NY: Guilford Press.

Burr, J., Shephard, R., Cornish, S., Vatanparast, H., and Chilibeck, P. (2012a). Arthritis, osteoporosis, and low back pain: evidence-based clinical risk assessment for physical activity and exercise clearance. Can. Fam. Physician 58, 59-62.

Burr, J., Shephard, R. J., and Riddell, M. C. (2012b). Physical activity in type 1 diabetes mellitus: assessing risks for physical activity clearance and prescription. Can. Fam. Physician 58, 533-535.

Carnethon, M. R. (2009). Physical activity and cardiovascular disease: how much is enough? Am. J. Lifestyle Med. 3(Suppl. 1), 44S-49S. doi: 10.1177/ 1559827609332737

Celis-Merchán, G. A. (2006). Adaptación al español de la escala revisada de motivos para la actividad física (MPAM-R) y el cuestionario de clima deportivo (SCQ). Adv. Med. 4, 73-90.

Chen, P. Y., Yang, C. M., and Morin, C. M. (2015). Validating the crosscultural factor structure and invariance property of the insomnia severity index: evidence based on ordinal EFA and CFA. Sleep Med. 16, 598-603. doi: 10.1016/ j.sleep.2014.11.016

Colberg, S. R., Sigal, R. J., Fernhall, B., Regensteiner, J. G., Blissmer, B. J., Rubin, R. R., et al. (2010). Exercise and type 2 diabetes: the american college of sports medicine and the american diabetes association: joint position statement. Diabetes Care 33, e147-e167. doi: 10.2337/dc10-9990

Diaz, K. M., and Shimbo, D. (2013). Physical activity and the prevention of hypertension. Curr. Hypertens. Rep. 15, 659-668. doi: 10.1007/s11906-0130386-8

DiStefano, C., Zhu, M., and Mîndrilã, D. (2009). Understanding and using factor scores: considerations for the applied researcher. Pract. Assess. Res. Eval. 14, $1-11$.

Field, A. (2009). Discovering Statistics using SPSS. London: SAGE.

Gonçalves, M. P., and Alchieri, J. C. (2010). Adaptação e validação da escala de motivação à prática de atividades físicas (MPAM-R). Aval. Psicol. 9, 129-138.

Hagger, M., and Chatzisarantis, N. (2008). Self-determination theory and the psychology of exercise. Int. Rev. Sport Exerc. Psychol. 1, 79-103. doi: 10.1080/ 17509840701827437

Hallal, P. C., Andersen, L. B., Bull, F. C., Guthold, R., Haskell, W., and Ekelund, U. (2012). Global physical activity levels: surveillance progress, pitfalls, and prospects. Lancet 380, 247-257. doi: 10.1016/S0140-6736(12)60646-1

Hopkins, W. G. (2000). Measures of reliability in sports medicine and science. Sports Med. 30, 1-15. doi: 10.2165/00007256-200030010-00001

Janssen, I., and Leblanc, A. G. (2010). Systematic review of the health benefits of physical activity and fitness in school-aged children and youth. Int. J. Behav. Nutr. Phys. Act. 7:40. doi: 10.1186/1479-5868-7-40

Kline, R. B. (2011). Principles and Practice of Structural Equation Modelling. London: The Guilford Press.

Lakka, T. A., and Bouchard, C. (2005). "Physical activity, obesity and cardiovascular diseases," in Handbook of Experimental Pharmacology, ed. A. von Eckardstein (Berlin: Springer), 137-163. doi: 10.1007/3-54027661-0_4

Lee, I. M., Shiroma, E. J., Lobelo, F., Puska, P., Blair, S. N., and Katzmarzyk, P. T. (2012). Effect of physical inactivity on major non-communicable diseases worldwide: an analysis of burden of disease and life expectancy. Lancet 380, 219-229. doi: 10.1016/S0140-6736(12)61031-9
Lonsdale, C., Hodge, K., and Rose, E. A. (2008). The behavioral regulation in sport questionnaire (BRSQ): instrument development and initial validity evidence. J. Sport Exerc. Psychol. 30, 323-355. doi: 10.1123/jsep.30.3.323

Molanorouzi, K., Khoo, S., and Morris, T. (2015). Motives for adult participation in physical activity: type of activity, age, and gender. BMC Public Health 15, 66. doi: 10.1186/s12889-015-1429-7

Murcia, J. A. M., Gimeno, E. C., and Camacho, A. M. (2007a). Measuring self-determination motivation in a physical fitness setting: validation of the behavioral regulation in exercise questionnaire-2 (BREQ-2) in a Spanish sample. J. Sports Med. Phys. Fit. 47, 366-374.

Murcia, J. A. M., Gimeno, E. C., and Camacho, A. M. (2007b). Validación de la escala de medida de los motivos para la actividad física-revisada en españoles: diferencias por motivos de participación. An. Psicol. 23, 167-176.

Pelletier, L. G., Rocchi, M. A., Vallerand, R. J., Deci, E. L., and Ryan, R. M. (2013). Validation of the revised sport motivation scale (SMS-II). Psychol. Sport Exerc. 14, 329-341. doi: 10.1016/j.psychsport.2012.12.002

Penedo, F. J., and Dahn, J. R. (2005). Exercise and well-being: a review of mental and physical health benefits associated with physical activity. Curr. Opin. Psychiatry 18, 189-193. doi: 10.1097/00001504-200503000-00013

Ryan, R. M., and Deci, E. L. (2000a). Intrinsic and extrinsic motivations: classic definitions and new directions. Contemp. Educ. Psychol. 25, 54-67. doi: 10.1006/ ceps. 1999.1020

Ryan, R. M., and Deci, E. L. (2000b). Self-determination theory and the facilitation of intrinsic motivation, social development, and well-being. Am. Psychol. 55, 68-78. doi: 10.1037/0003-066X.55.1.68

Ryan, R. M., Frederick, C. M., Lepes, D., Rubio, N., and Sheldon, K. M. (1997). Intrinsic motivation and exercise adherence. Int. J. Sports Psychol. 28, 335-354.

Shi, Y., Li, T., Wang, Y., Zhou, L., Qin, Q., Yin, J., et al. (2015). Household physical activity and cancer risk: a systematic review and dose-response meta-analysis of epidemiological studies. Sci. Rep. 5:14901. doi: 10.1038/srep14901

Sijtsma, K. (2009). On the use, the misuse, and the very limited usefulness of Cronbach's alpha. Psychometrika 74, 107-120. doi: 10.1007/s11336-008-9101-0

Sperber, A. D. (2004). Translation and validation of study instruments for crosscultural research. Gastroenterology 126(Suppl. 1), S124-S128. doi: 10.1053/j. gastro.2003.10.016

Tavakol, M., and Dennick, R. (2011). Making sense of Cronbach's alpha. Int. J. Med. Educ. 2, 53-55. doi: 10.5116/ijme.4dfb.8dfd

Vogel, T., Brechat, P. H., Lepretre, P. M., Kaltenbach, G., Berthel, M., and Lonsdorfer, J. (2009). Health benefits of physical activity in older patients: a review. Int. J. Clin. Pract. 63, 303-320. doi: 10.1111/j.1742-1241.2008.01957.x

Warburton, D. E., Nicol, C. W., and Bredin, S. S. (2006). Health benefits of physical activity: the evidence. CMAJ 174, 801-809. doi: 10.1503/cmaj.051351

Wilson, P. M., Rodgers, W. M., and Fraser, S. N. (2002). Cross-validation of the revised motivation for physical activity measure in active women. Res. Q. Exerc. Sport 73, 471-477. doi: 10.1080/02701367.2002.10609048

Conflict of Interest Statement: The authors declare that the research was conducted in the absence of any commercial or financial relationships that could be construed as a potential conflict of interest.

Copyright (c) 2017 Albuquerque, Lopes, de Paula, Faria, Pereira and da Costa. This is an open-access article distributed under the terms of the Creative Commons Attribution License (CC BY). The use, distribution or reproduction in other forums is permitted, provided the original author(s) or licensor are credited and that the original publication in this journal is cited, in accordance with accepted academic practice. No use, distribution or reproduction is permitted which does not comply with these terms. 